\title{
Long-term tolerability of once-monthly injectable paliperidone palmitate in subjects with recently diagnosed schizophrenia
}

This article was published in the following Dove Press journal:

Neuropsychiatric Disease and Treatment

24 August 2012

Number of times this article has been viewed

\author{
Jennifer Kern Sliwa' \\ Cynthia A Bossie' \\ Dong-Jing $\mathrm{Fu}^{\prime}$ \\ Ibrahim Turkoz ${ }^{2}$ \\ Larry Alphs'
}

'Janssen Scientific Affairs LLC,

${ }^{2}$ Janssen Research and Development, LLC, Titusville, NJ, USA

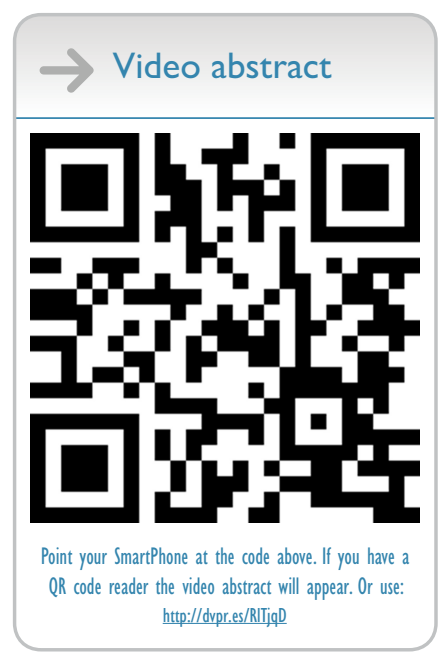

Correspondence: Cynthia A Bossie Janssen Scientific Affairs,

I I 25 Trenton-Harbourton Road,

Titusville, NJ 08560, USA

Tel +I 6097303402

Email cbossie@its.jnj.com
Background: A post hoc analysis from a multiphase trial with open-label transition and maintenance phases, a double-blind relapse prevention phase, and an optional open-label extension examined the long-term tolerability with continuous once-monthly injectable paliperidone palmitate $39,78,117$, or $156 \mathrm{mg}(25,50,75$, or $100 \mathrm{mg}$ equivalents [mg eq] of paliperidone $)$ in subjects with recently diagnosed $(\leq 5$ years; $n=216)$ versus chronic illness $(>5$ years; $n=429)$ schizophrenia.

Methods: Adverse events reported at a $\geq 2 \%$ margin between subgroups were identified. Relative risks (in the recently diagnosed compared with the chronically ill) and 95\% confidence intervals (CI) were determined, and CI not including 1 were considered potentially significant.

Results: In both subgroups, the mean monthly dose was $109 \mathrm{mg}$ (69.9 mg eq). Continuous mean exposures were $333.9 \pm 271.9$ and $308.7 \pm 278.3$ days in the recently diagnosed and chronic illness subgroups, respectively. Using the criteria outlined in the methods, nasopharyngitis was a potentially significant event reported in more chronically ill than recently diagnosed subjects at months $6,9,12$, and endpoint (7.2\% versus $2.8 \%$; relative risk $0.384 ; 95 \%$ CI $0.163-0.907)$. Influenza (2.8\% versus $0.7 \%$; relative risk $3.9 ; 95 \%$ CI $1.003-15.730)$ and amenorrhea $(3.2 \%$ versus $0.9 \%$; relative risk 3.476 ; $95 \%$ CI $1.029-11.744$ ) at endpoint were potentially significant events in more recently diagnosed than chronically ill subjects. Mean weight changes, sedation/somnolence, any extrapyramidal symptom-related or glucose-related events were generally similar between the groups. The mean prolactin level increased in both sexes in both subgroups (changes from baseline of $+41.8 \mathrm{ng} / \mathrm{mL}$ and $+26.5 \mathrm{ng} / \mathrm{mL}$ in recently diagnosed and chronic illness females and $+12.3 \mathrm{ng} / \mathrm{mL}$ and $+15.1 \mathrm{ng} / \mathrm{mL}$ in recently diagnosed and chronic illness males, respectively), and were higher in females with recently diagnosed illness than in females who were chronically ill ( $P=0.0002$ at endpoint). Prolactin-related events were reported by $7.9 \%$ of recently diagnosed subjects with schizophrenia and $3.5 \%$ of those who were chronically ill.

Conclusion: The long-term tolerability of paliperidone palmitate was generally similar in recently diagnosed schizophrenia subjects and those with more chronic illness, with the exception of some prolactin-related measures.

Keywords: paliperidone palmitate, long-acting antipsychotic, recently diagnosed, early illness, schizophrenia

\section{Introduction}

In subjects with schizophrenia, the first 5-10 years of illness has been identified as a critical period for effective intervention to prevent biological as well as psychosocial deterioration, ${ }^{1,2-7}$ optimize outcomes, ${ }^{1,8-12}$ reduce the risk for symptom relapse, ${ }^{13-17}$ and possibly mitigate disease progression. ${ }^{5,18}$ However, during these early years, there are 
some barriers to effective intervention and treatment. These patients are often nonadherent with medications due to lack of insight into both their illness and the need for treatment, as well as forgetfulness, lack of social support, and personal choice. ${ }^{19}$ Whereas recently diagnosed patients are often more responsive to antipsychotic medications than those with chronic schizophrenia, ${ }^{14,16,20,21}$ they may also be more sensitive to adverse drug effects. ${ }^{5,22-28}$ In particular, reports suggest that various extrapyramidal symptoms (EPS), weight gain, prolactin-related effects, and sedation are more frequent and problematic for persons early in their illness. ${ }^{8,29-36}$

Because early in the course of schizophrenia illness patients poorly adhere to daily therapy, it has been suggested that long-acting injectable antipsychotics may be a particularly appropriate treatment option for these patients. In addition to eliminating the daily need to remember to be adherent, these agents allow clinicians and caregivers to have immediate awareness of noncompliance. Guaranteed onboarding of antipsychotic medication allows clinicians to make more informed treatment decisions. Further, the long half-lives of these agents provide a wider window for missed doses (days or weeks rather than hours) before plasma levels drop below critical thresholds, where the risks for relapse, hospitalization, and suicide may be increased. . $^{21,37-41}$

On the other hand, tolerability is often a key factor in medication choice for recently diagnosed patients and longacting agents may pose such concerns for both clinicians and patients. Unfortunately, few studies have assessed the safety of injectable medications in patients with a recent onset ${ }^{42-45}$ or first episode of psychosis, ${ }^{46}$ and their use in recently diagnosed patients is generally limited. Despite well known adherence issues with oral medications and an associated high risk for subsequent relapse, ${ }^{2,37}$ long-acting agents are often reserved for more treatment-refractory patients.

Paliperidone palmitate (Janssen Pharmaceuticals, Titusville, NJ), the palmitate ester of paliperidone, is a longacting, once-monthly, injectable, atypical antipsychotic for the treatment of schizophrenia. ${ }^{47}$ Doses of paliperidone palmitate may be expressed as milligrams $(\mathrm{mg})$ or as milligram equivalents (mg eq) of the pharmacologically active fraction, paliperidone $(39,78,117,156$, and $234 \mathrm{mg}$ of paliperidone palmitate corresponding to $25,50,75,100$, and $150 \mathrm{mg}$ eq of active paliperidone). Its use for both acute and maintenance treatment of schizophrenia has been demonstrated in short-term ${ }^{48-51}$ and longer-term ${ }^{52-54}$ studies. To date, there are no published prospective studies of paliperidone palmitate in patients experiencing their first episode or early in their schizophrenia illness. A recent post hoc analysis of a large, international, 13-week, placebo-controlled trial reported on tolerability and efficacy of paliperidone palmitate in subjects with recently diagnosed schizophrenia receiving the recommended initiation doses (234 $\mathrm{mg}$ [150 $\mathrm{mg}$ eq] day 1 and $156 \mathrm{mg}$ [100 mg eq] day 8). ${ }^{55}$ These data are informative but do not address longer-term tolerability concerns. A recently completed relapse prevention trial ${ }^{52,54}$ of paliperidone palmitate provides valuable long-term exposure data that can help to address this question. A post hoc safety and tolerability analysis of this trial focusing on the recently diagnosed subgroup as compared with the more chronically ill subpopulation is reported herein.

\section{Materials and methods Design}

This was a post hoc analysis of a five-phase international trial conducted from March 2005 to February 2008 (NCT00111189). Key subject inclusion criteria included being aged $18-65$ years and a body mass index $\geq 15.0 \mathrm{~kg} /$ $\mathrm{m}^{2}$, a diagnosis of schizophrenia for at least one year before screening, and a total Positive and Negative Syndrome Scale score below 120 at screening and at baseline, with no lower score eligibility limit. The study was conducted in accordance with the Declaration of Helsinki and consistent with Good Clinical Practice. Additional design details have been previously reported. ${ }^{52,54}$

\section{Study phases and treatments}

The five study phases (Figure 1) were: a screening/washout phase up to 7 days; an open-label, 9-week, transition phase for switching to paliperidone palmitate at $78 \mathrm{mg}$ (50 mg eq) on days 1 and 8, followed by flexible dosing of 39,78 , or $156 \mathrm{mg}$ $(25,50$, or $100 \mathrm{mg}$ eq) at week 5; an open-label 24-week maintenance phase with flexible paliperidone palmitate dosing $(39,78$, or $156 \mathrm{mg}$ monthly [25, 50, or $100 \mathrm{mg}$ eq]) for the first 12 weeks followed by the established maintenance dose for the second 12 weeks; a randomized (1:1 ratio), double-blind, placebo-controlled, relapse prevention phase of variable duration (up to 63 weeks) for subjects stabilized on a fixed paliperidone palmitate dose during the maintenance phase; and an optional open-label extension phase up to 52 weeks with flexible paliperidone palmitate dosing $(39,78$, 117 , or $156 \mathrm{mg}[25,50,75$, or $100 \mathrm{mg}$ eq]). Subjects who experienced a relapse, completed the relapse prevention phase, or received at least one injection of paliperidone palmitate when enrollment in the study was stopped were eligible to enter the open-label extension phase. 


\section{Post hoc population and tolerability assessments}

The recently diagnosed subgroup was defined as those subjects within 5 years of their initial diagnosis of schizophrenia. The chronically ill subgroup included those subjects $>5$ years out from their initial diagnosis of schizophrenia. This analysis was limited to subjects who received paliperidone palmitate continuously from entry into the open-label transition phase to study completion or discontinuation (Figure 1).

Tolerability was evaluated by treatment-emergent adverse events reported from the open-label transition phase baseline through months $1,3,6,9$, and 12 and to the open-label extension endpoint. These included reports of adverse events (either reported by the subject voluntarily or collected by means of interviewing subjects in a nondirected manner), clinical laboratory tests, vital sign measurements, extrapyramidal symptom rating scales (Simpson Angus Scale, Barnes Akathisia Rating Scale, and Abnormal Involuntary Movement Scale) and findings on physical examination. Changes from baseline in physical assessments of weight and body mass index, and measurement of serum prolactin and glucose levels were recorded.

\section{Analysis sets and statistical analysis}

The safety population consisted of 216 recently diagnosed subjects and 429 chronically ill subjects who received paliperidone palmitate continuously from study entry through study completion or discontinuation. Demographic and baseline characteristics between groups were compared by $t$-test for continuous variables and Chi-square or Fisher's exact test for categorical variables. Between-subgroup differences in continuous measures for post-baseline scores were assessed using analysis of covariance (model with fixed effects) for recently diagnosed versus chronically ill subgroups and country, and the baseline (transition phase) value as a covariate. Change from baseline within groups was assessed by paired $t$-test. Mean monthly doses of paliperidone palmitate (for days on drug only) and exposure in days were summarized.

Frequencies and percentages of adverse events were summarized from the time of first injection to months $1,3,6,9$,

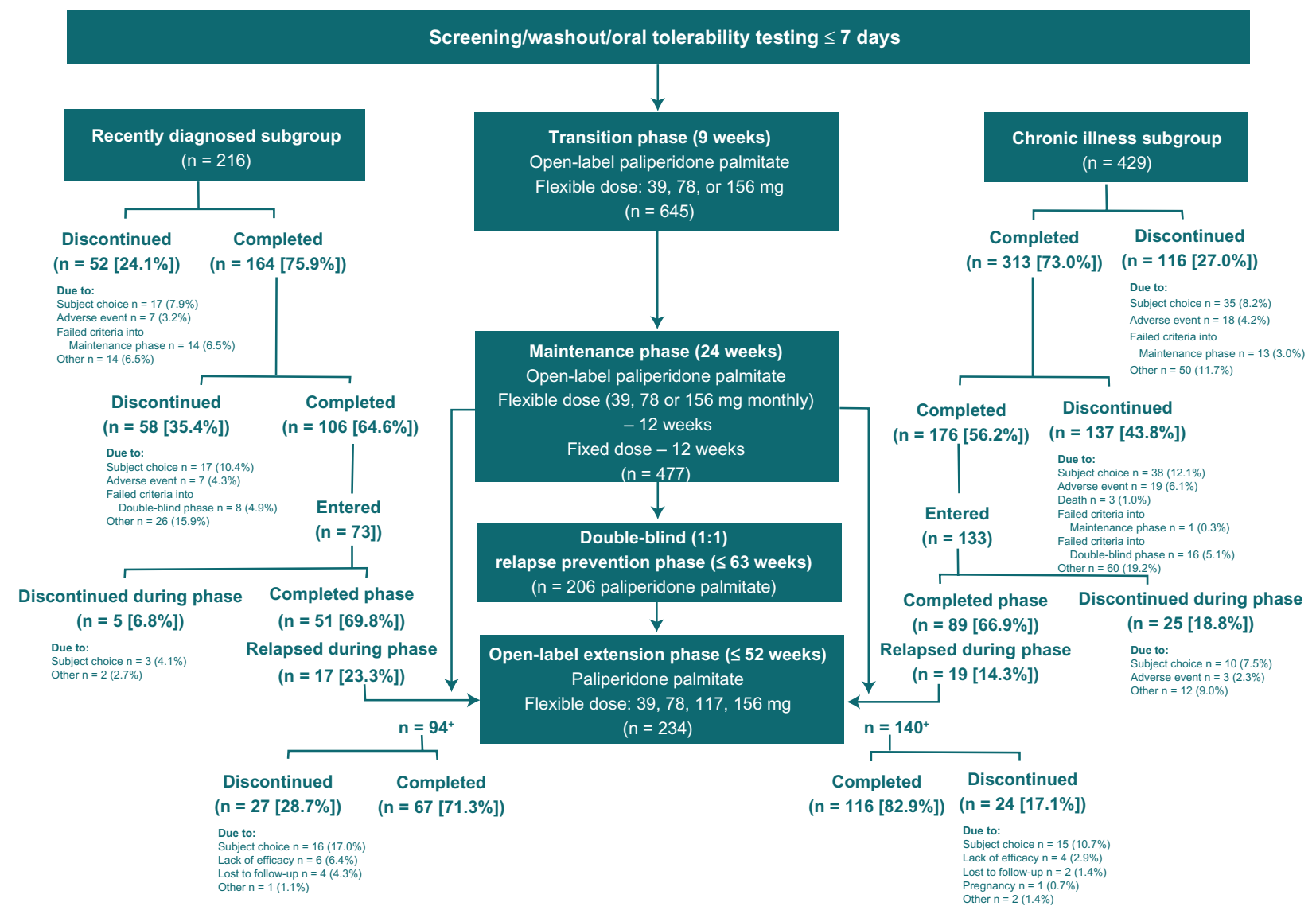

Figure I Study design and subject disposition in recently diagnosed and chronically ill subgroups treated continuously with paliperidone palmitate.

Note: +74 subjects who were in the maintenance phase at the time of its termination and were considered to have completed this phase were eligible to enroll in the openlabel extension without entering the double-blind phase. Of the 58 that enrolled, 26 were recently diagnosed and 32 were in the chronic illness subgroup. 
and 12 and endpoint. Adverse events reported during these time periods that occurred at a margin of $\geq 2 \%$ between the subgroups are reported and displayed by percentage rate in each treatment subgroup. The relative risk (RR) and 95\% confidence interval $[\mathrm{CI}]$ in the recently diagnosed group compared with the chronically ill subgroup were determined. Unadjusted CI were utilized as a flagging device to identify potentially significant adverse events when the unadjusted CI did include 1. Any adjustment for multiplicity was considered to be counterproductive for identifying potential safety risks.

Any events related to extrapyramidal symptoms, glucose, or prolactin were also summarized. Logistic regression models examined the association between probability of these events with demographic and baseline characteristics that differed between subgroups. These included diagnosis status (recently diagnosed versus chronically ill), age, age at time of diagnosis of schizophrenia, race (black versus Caucasian or other versus Caucasian), weight, body mass index, and smoking status (yes or no).

Changes in weight and glucose and prolactin levels from transition phase baseline through open-label extension were summarized. In addition to analysis of covariance at endpoint, repeated-measures analysis of covariance assessed between-group differences using observed scores to compare mean response profiles over time. The $P$ values for the group effect and group-by-visit interactions were provided. The group effect measured the deviation from the hypothesis of equality of mean changes between groups, averaged over the treatment duration. The group-by-visit interaction tested the hypothesis of parallel response profiles over time. Multiple linear regression models examined relationships between changes in weight, and glucose and prolactin levels, with demographic and baseline characteristics that were found to be different at baseline.

\section{Results}

\section{Subject baseline demographics, disposition, and dosing}

Subjects in the recently diagnosed subgroup were younger than the chronically ill subgroup at study entry, with an older age at the time of diagnosis of schizophrenia, and with a lower weight and body mass index (Table 1). There was a higher percentage of Caucasians and a lower percentage of smokers in the recently diagnosed subgroup than in the chronically ill subgroup. The mean years of illness was $2.9 \pm 1.5$ (range 1.0-5.0) in the recently diagnosed subgroup and
Table I Transition baseline demographics and characteristics that differed between subgroups

\begin{tabular}{|c|c|c|c|}
\hline & $\begin{array}{l}\text { Recently } \\
\text { diagnosed } \\
(n=216)\end{array}$ & $\begin{array}{l}\text { Chronically ill } \\
(n=429)\end{array}$ & $P$ value \\
\hline Age, years (mean $\pm S D)$ & $31.0 \pm 9.3$ & $40.6 \pm 9.7$ & $<0.001$ \\
\hline $\begin{array}{l}\text { Age distribution, } \\
\text { years, } n(\%)\end{array}$ & & & $<0.000$ I \\
\hline $18-25$ & $68(31.5 \%)$ & $27(6.3 \%)$ & \\
\hline $26-50$ & $142(65.7 \%)$ & 336 (78.3\%) & \\
\hline$>50$ & $6(2.8 \%)$ & $66(15.4 \%)$ & \\
\hline Race, n (\%) & & & $<0.001$ \\
\hline Caucasian & $156(72.2 \%)$ & $232(54.1 \%)$ & \\
\hline Black & $13(6.0 \%)$ & $107(24.9 \%)$ & \\
\hline Asian & 43 (19.9\%) & $74(17.2 \%)$ & \\
\hline Other & $4(1.9 \%)$ & $16(3.7 \%)$ & \\
\hline Weight, kg (mean \pm SD) & $75.3 \pm 15.94$ & $80.5 \pm 20.21$ & $<0.0003$ \\
\hline $\mathrm{BMI}, \mathrm{kg} / \mathrm{m}^{2}($ mean $\pm \mathrm{SD})$ & $25.9 \pm 4.92$ & $27.6 \pm 6.23$ & $<0.0001$ \\
\hline Current smoker, n (\%) & $92(42.6 \%)$ & $246(57.3 \%)$ & $=0.0004$ \\
\hline $\begin{array}{l}\text { Age at schizophrenia } \\
\text { diagnosis, years } \\
\text { (mean } \pm S D \text { ) }\end{array}$ & $28.0 \pm 9.1$ & $24.4 \pm 7.7$ & $<0.000$ I \\
\hline
\end{tabular}

Abbreviations: BMI, body mass index; SD, standard deviation.

$16.2 \pm 8.1$ (range 6.0-47.0) in the chronically ill subgroup. The subgroups were similar with respect to sex (male $60.2 \%$ and $58.0 \%$, respectively), mean total Positive and Negative Syndrome Scale score (70.7 and 73.3, $P=0.0811$, respectively), and Clinical Global Impressions Scale scores (not ill to moderate in $87.0 \%$ and $81.8 \%$, respectively). Completion rates were generally similar between the subgroups during each study phase (Figure 1). Among subjects receiving paliperidone palmitate who entered the double-blind relapse prevention phase, the time to relapse was not significantly different between the recently diagnosed and chronically ill subgroups ( $P=0.0999$, log-rank test).

The mean monthly dose was similar in each subgroup (approximately $109 \mathrm{mg}$ [69.9 mg eq]), with a mean duration of exposure of $333.9 \pm 271.9$ days in the recently diagnosed subgroup and $308.7 \pm 278.3$ days in the chronically ill subgroup. During the study, $42.1 \%$ of those in the recently diagnosed subgroup received benzodiazepines and $10.2 \%$ received medications for extrapyramidal symptoms, respectively. In the chronically ill subgroup, rates were $46.4 \%$ for benzodiazepines and $17.0 \%$ for medications used to treat extrapyramidal symptoms.

\section{Reported adverse events}

During the month following the first injection, $31.5 \%$ (68 of 216) of recently diagnosed and 42.7\% (183 of 429) of subjects in the chronically ill subgroup reported an adverse 
Table 2 Subjects with at least one adverse event in the recently diagnosed and chronically ill subgroups (from time since first injection to specified time point)

\begin{tabular}{lllr}
\hline Intervals from first injection & $\begin{array}{l}\text { Recently diagnosed } \\
(\mathbf{n = 2 1 6 )}\end{array}$ & $\begin{array}{l}\text { Chronically ill } \\
(\mathbf{n}=\mathbf{4 2 9})\end{array}$ & RR $^{\mathbf{a}}(\mathbf{9 5 \%} \mathbf{C l})$ \\
\hline To month I & $68(31.5 \%)$ & $183(42.7 \%)$ & $0.738(0.589-0.924)$ \\
To month 3 & $112(51.9 \%)$ & $264(61.5 \%)$ & $0.843(0.726-0.978)$ \\
To month 6 & $129(59.7 \%)$ & $296(69.0 \%)$ & $0.866(0.763-0.982)$ \\
To month 9 & $141(65.3 \%)$ & $312(72.7 \%)$ & $0.898(0.801-1.005)$ \\
To month I2 & $148(68.5 \%)$ & $320(74.6 \%)$ & $0.919(0.826-1.021)$ \\
To open-label extension endpoint & $153(70.8 \%)$ & $330(76.9 \%)$ & $0.921(0.833-1.018)$ \\
\hline
\end{tabular}

Notes: aRecently diagnosed subgroup compared with the chronically ill subgroup. Data are cumulative; each interval includes events from the previous interval. Abbreviations: $\mathrm{Cl}$, confidence interval; $\mathrm{RR}$, relative risk.

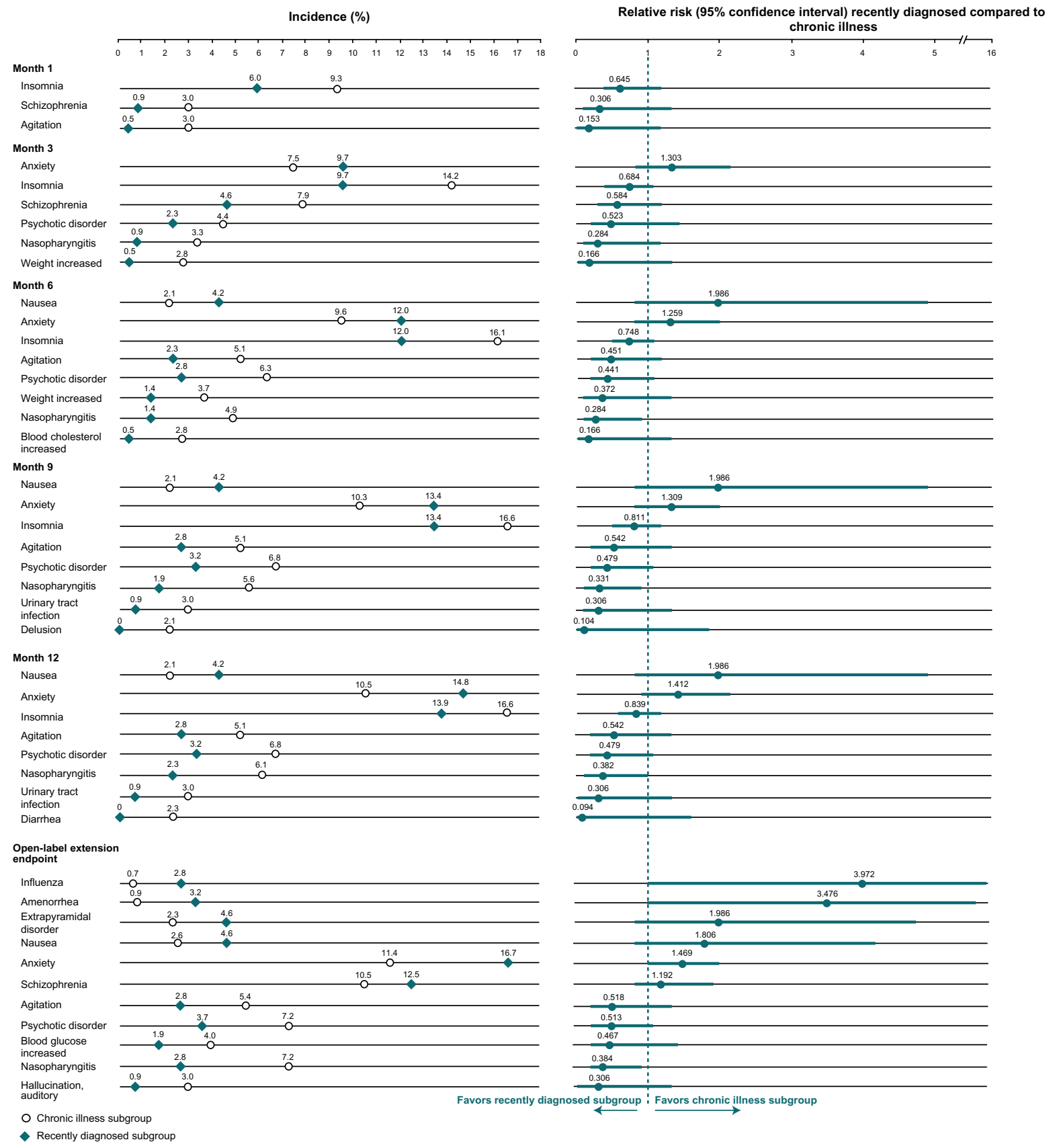

Figure 2 Percentage, relative risk (recently diagnosed versus chronic illness), and $95 \%$ confidence intervals of adverse events reported by a margin of $\geq 2 \%$ in recently diagnosed or chronically ill subgroups. 
event (Table 2). In general, incidence rates, RR, and 95\% CI suggested that adverse events were less likely in the recently diagnosed subgroup than in the chronically ill subgroup at each time interval.

In the month following the first injection, no adverse events were reported at a margin of $\geq 2 \%$ in more of the recently diagnosed subjects than in those with chronic illness (Figure 2). Insomnia, worsening of schizophrenia, and agitation were reported at a margin of $\geq 2 \%$ in more of the chronically ill subjects than in recently diagnosed subjects. These differences in incidence were not considered potentially significant based upon the $95 \%$ CI. Nasopharyngitis was reported by more subjects with chronic illness than by those in the recently diagnosed subgroup of subjects at months $6(4.9 \%$ versus $1.4 \%$; RR 0.28 ; 95\% CI $0.086-0.941$ respectively), 9 (5.6\% versus $1.9 \%$; RR 0.33 ; 95\% CI $0.116-0.942)$, and 12 (6.1\% versus $2.3 \%$; RR 0.38 ; 95\% CI $0.149-0.981)$, and endpoint (7.2\% versus 2.8\%; RR 0.38; 95\% CI 0.163-0.907); the $95 \%$ CI did not include 1 and were considered potentially significant. Influenza (2.8\% versus $0.7 \%$; RR 3.97; 95\% CI $1.003-15.730)$ and amenorrhea (3.2\% versus $0.9 \%$; RR 3.48; 95\% CI 1.029-11.744) were reported by more subjects in the recently diagnosed subgroup at endpoint. Given that the 95\% CI did not include 1 , these events were also considered potentially significantly different between subgroups.

In the recently diagnosed subgroup, sedation was reported by none, one, or two subjects at each time point $(0.0 \%-0.93 \%)$, with somnolence reported by one or two subjects at each time point $(0.46 \%-0.93 \%)$, and five subjects at endpoint $(2.31 \%)$. In the chronically ill subgroup, sedation was reported by two subjects at each time point $(0.47 \%)$, with somnolence reported by $1-5$ subjects at each time point $(0.23 \%-1.17 \%)$.

\section{Events related to extrapyramidal symptoms}

Extrapyramidal symptom-related adverse event rates included parkinsonism, hyperkinesia, dystonia, tremor, and dyskinesia. Rates of any extrapyramidal symptom-related events were numerically lower in the recently diagnosed subgroup at each period assessed (through months 1, 3, 6, 9, and 12 and open-label extension). Rates ranged from $2.3 \%$ to $9.3 \%$ in the recently diagnosed subgroup and from $5.8 \%$ to $12.6 \%$ in the chronically ill subgroup (Figure 3 ). Rates of individual extrapyramidal symptom-related events and their specific preferred terms are summarized in Table 3. Among the specific preferred terms, nonspecific extrapyramidal disorder was reported by more recently diagnosed subjects
Table 3 Extrapyramidal symptom-related adverse events from first injection through open-label extension phase, in recently diagnosed and chronically ill subgroups

\begin{tabular}{|c|c|c|}
\hline $\begin{array}{l}\text { Extrapyramidal } \\
\text { adverse events and } \\
\text { preferred terms }\end{array}$ & $\begin{array}{l}\text { Recently } \\
\text { diagnosed } \\
(n=216)\end{array}$ & $\begin{array}{l}\text { Chronically ill } \\
(n=429)\end{array}$ \\
\hline Subjects with an event, ${ }^{a} \mathrm{n}(\%)$ & $20(9.3)$ & $54(12.6)$ \\
\hline \multicolumn{3}{|l|}{ Events } \\
\hline Parkinsonism & $12(5.6)$ & $24(5.6)$ \\
\hline Extrapyramidal disorder & $10(4.6)$ & $10(2.3)$ \\
\hline Hypertonia & $2(0.9)$ & $9(2.1)$ \\
\hline Musculoskeletal stiffness & 0 & $5(1.2)$ \\
\hline Drooling & 0 & $2(0.5)$ \\
\hline Muscle tightness & 0 & $2(0.5)$ \\
\hline Hyperkinesia & $5(2.3)$ & $19(4.4)$ \\
\hline Akathisia & $4(1.9)$ & $14(3.3)$ \\
\hline Restlessness & $\mathrm{I}(0.5)$ & $6(1.4)$ \\
\hline Dystonia & $2(0.9)$ & $8(1.9)$ \\
\hline Muscle spasms & $\mathrm{I}(0.5)$ & $4(0.9)$ \\
\hline Dystonia & 0 & $3(0.7)$ \\
\hline Oculogyric crisis & $\mathrm{I}(0.5)$ & $\mathrm{I}(0.2)$ \\
\hline Tremor & $\mathrm{I}(0.5)$ & $9(2.1)$ \\
\hline Tremor & $\mathrm{I}(0.5)$ & $9(2.1)$ \\
\hline Dyskinesia & $2(0.9)$ & $7(1.6)$ \\
\hline Dyskinesia & $\mathrm{I}(0.5)$ & $5(1.2)$ \\
\hline Muscle twitching & $\mathrm{I}(0.5)$ & I $(0.2)$ \\
\hline Tardive dyskinesia & 0 & $\mathrm{I}(0.2)$ \\
\hline
\end{tabular}

Notes: ${ }^{a} \mathrm{~A}$ subject experiencing more than one adverse event within a system organ class/preferred term is counted once within that system organ class/preferred term for incidence.

(4.6\%) than by chronically ill subjects $(2.3 \%)$, and akathisia was reported by more chronically ill subjects (3.3\%) than recently diagnosed subjects $(1.9 \%)$.

Logistic regression models showed that none of the baseline characteristics that differed between the subgroups was associated with risk of extrapyramidal symptom-related events (ie, age, $P=0.7057$; weight, $P=0.8921$; body mass index, $P=0.9823$; age at diagnosis of schizophrenia, $P=0.7727$; current smoking status, $P=0.3507$; and race [black, $P=0.0950$; other, $P=0.1602]$ ).

\section{Weight changes}

Weight changes (least squares mean \pm standard error) at endpoint were $2.6 \pm 0.9 \mathrm{~kg}$ in the recently diagnosed subgroup and $3.4 \pm 0.7 \mathrm{~kg}$ in the chronically ill subgroup $(P=0.42$; least squares mean difference $0.8 \pm 0.99,95 \%$ CI: $-1.15-2.75)$. Observed scores at each time point were evaluated using repeated-measures analysis of covariance. Average changes from baseline to endpoint between groups were similar (between-group comparison, $P=0.4342$ ); this finding did not differ throughout the trial (group-by-visit interaction, $P=0.9520$ ). Linear regression models assessing the impact of baseline differences did not reveal any potential 
Table 4 Glucose-related events from the first injection through open-label extension phase ${ }^{a}$

\begin{tabular}{|c|c|c|}
\hline & $\begin{array}{l}\text { Recently } \\
\text { diagnosed } \\
(n=216)\end{array}$ & $\begin{array}{l}\text { Chronically ill } \\
(n=429)\end{array}$ \\
\hline $\begin{array}{l}\text { Subjects with a glucose-related } \\
\text { adverse event, } n(\%)\end{array}$ & $6(2.8)$ & $22(5.1)$ \\
\hline \multicolumn{3}{|c|}{ Specific glucose-related event, n (\%) } \\
\hline Blood glucose increased & $4(1.9)$ & $17(4.0)$ \\
\hline Hyperglycemia & I (0.5) & $3(0.7)$ \\
\hline Diabetes mellitus & I $(0.5)$ & $2(0.5)$ \\
\hline Increased insulin requirement & $2(0.9)$ & $\mathrm{I}(0.2)$ \\
\hline Diabetic complication & $0(0)$ & $\mathrm{I}(0.2)$ \\
\hline Glucose tolerance impaired & $0(0)$ & I $(0.2)$ \\
\hline Type 2 diabetes mellitus & $0(0)$ & I $(0.2)$ \\
\hline
\end{tabular}

Notes: ${ }^{\mathrm{A}} \mathrm{A}$ subject experiencing more than one adverse event within a system organ class/preferred term is counted once within that system organ class/preferred term for incidence.

associations (ie, age, $P=0.5117$; weight, $P=0.1504$; body mass index, $P=0.6557$; age at schizophrenia diagnosis, $P=0.9309$; current smoking status, $P=0.1172$; and race, [black, $P=0.5444$; other, $P=0.3842$ ]).

\section{Glucose-related measures}

Rates of glucose-related adverse events were 5.1\% (22 of 429) in the chronically ill subjects and $2.8 \%$ (6 of 216) in recently diagnosed subjects, with "blood glucose increased" being the most frequent ( $4.0 \%$ versus $1.9 \%$, Table 4$)$. In logistic regression models, age $(P<0.0001$; odds ratio [OR] $1.087 ; 95 \%$ CI $1.047-1.129)$ had a significant association with incidence of glucose-related adverse events (one-year increase in age is associated with an $8.7 \%$ increase in odds of experiencing "blood glucose increased"), whereas body mass index $(P=0.0516$; OR 1.057 ; 95\% CI $1.000-1.118)$ and age at diagnosis of schizophrenia $(P=0.0578$; OR 1.040 95\% CI 0.999-1.082) showed trends towards significance.
Other baseline characteristics had no impact (ie, weight, $P=0.4310$; current smoking status, $P=0.6082$; and race [black, $P=0.1737$; other, $P=0.0810$ ]).

Mean glucose levels at open-label endpoint were not significantly different between the groups (least squares mean difference $-0.1,95 \% \mathrm{CI}-0.61-0.32, P=0.5436$ ). Regression models showed that age $(P=0.0126$, regression coefficient $0.025 \pm 0.010$ ) and age at diagnosis of schizophrenia $(P=0.0021$, regression coefficient $0.042 \pm 0.014)$ were associated with changes at endpoint.

\section{Prolactin-related measures}

Prolactin levels increased in both sexes in both subgroups. Mean prolactin values were consistently higher in recently diagnosed female subjects compared with chronically ill female subjects (Table 5). Potentially prolactin-related adverse events were reported by $7.9 \%$ of recently diagnosed subjects compared with $3.5 \%$ of chronically ill subjects through endpoint (Table 6). The most commonly reported events were amenorrhea (7 [3.2\%] and $4[0.9 \%]$, respectively) and galactorrhea (2 [0.9\%] and $6[1.4 \%]$, respectively).

\section{Discussion}

The primary objective of this post hoc analysis was to examine the long-term tolerability of once-monthly injectable paliperidone palmitate in subjects with a more recent diagnosis of schizophrenia compared with those with a longer duration of illness. Among the range of events anticipated to occur more commonly in the recently diagnosed subgroup, only events related to prolactin elevation emerged as more likely to be increased. Weight increases, sedation/somnolence, overall extrapyramidal symptoms, and glucose-related events did not occur at a greater rate in recently diagnosed subjects. Strengths of this analysis include the length and

Table 5 Mean prolactin levels at transition baseline and open-label endpoint by sex in the recently diagnosed and chronically ill subgroups

\begin{tabular}{|c|c|c|c|c|c|}
\hline & $\begin{array}{l}\text { Prolactin levels }(\mathrm{ng} / \mathrm{mL})^{\mathrm{a}} \\
\text { LSM (SE) }\end{array}$ & Recently diagnosed & Chronic illness & $\begin{array}{l}\text { LSM difference } \\
\text { and } 95 \% \mathrm{Cl}\end{array}$ & $\begin{array}{l}\text { Between-group } \\
\text { Pvalue }^{\mathrm{b}}\end{array}$ \\
\hline \multirow[t]{4}{*}{ Females } & Transition baseline & $39.1(5.14)$ & $30.8(4.2 I)$ & $8.3(-2.52-19.16)$ & 0.1321 \\
\hline & Open-label endpoint & $82.2(7.95)$ & $66.8(7.25)$ & & \\
\hline & Change from baseline & $41.8(7.95)^{c}$ & $26.5(7.25)^{c}$ & $15.3(-2.49-33.14)$ & 0.0901 \\
\hline & Repeated-measures group, $P$ & 02; group-by-visit intera & $P=0.0590$ & & \\
\hline \multirow[t]{4}{*}{ Males } & Transition baseline & $17.8(2.43)$ & $12.5(2.08)$ & $5.3(0.04-10.64)$ & 0.0483 \\
\hline & Open-label endpoint & $30.6(4.29)$ & $33.4(4.01)$ & & \\
\hline & Change from baseline & $12.3(4.29)^{c}$ & $15.1(4.01)^{c}$ & $-2.8(-12.11-6.45)$ & 0.5470 \\
\hline & Repeated-measures group, $P$ & 67; group-by-visit intera & $P=0.5728$ & & \\
\hline
\end{tabular}

Notes: aProlactin levels considered normal may vary between laboratories but are generally in the range of 2-29 $\mathrm{ng} / \mathrm{mL}$ in nonpregnant females and $2-18 \mathrm{ng} / \mathrm{mL}$ in $\mathrm{males}$; bbetween-subgroup comparisons are from analysis of covariance models with group (recently diagnosed versus chronically ill) and country as factors, and baseline value as a covariate; $c P<0.05$ for each change from transition baseline to open-label endpoint in the recently diagnosed and chronically ill subgroups from paired $t$-test. Abbreviations: $\mathrm{Cl}$, confidence interval; LSM, least squares mean; SE, standard error. 
Table 6 Potentially prolactin-related events from first injection through open-label extension phase ${ }^{a}$

\begin{tabular}{lll}
\hline Event & $\begin{array}{l}\text { Recently } \\
\text { diagnosed } \\
(\mathbf{n}=\mathbf{2} \text { I6) }\end{array}$ & $\begin{array}{l}\text { Chronic } \\
\text { illness } \\
\mathbf{( n = 4 2 9 )}\end{array}$ \\
\hline $\begin{array}{l}\text { Subjects reporting a potentially } \\
\text { prolactin-related adverse event, n (\%) }\end{array}$ & $17(7.9)$ & I5 (3.5) \\
Specific potentially prolactin-related event, $\mathbf{n}(\%)$ & \\
Amenorrhea & $7(3.2)$ & $4(0.9)$ \\
Galactorrhea & $2(0.9)$ & $6(I .4)$ \\
Menstruation irregular & $2(0.9)$ & $3(0.7)$ \\
Erectile dysfunction & $2(0.9)$ & $2(0.5)$ \\
Sexual dysfunction & $2(0.9)$ & $\mathrm{I}(0.2)$ \\
Oligomenorrhea & $\mathrm{I}(0.5)$ & $\mathrm{I}(0.2)$ \\
Breast pain & $\mathrm{I}(0.5)$ & $0(0)$ \\
Breast tenderness & $0(0)$ & $\mathrm{I}(0.2)$ \\
Gynecomastia & $\mathrm{I}(0.5)$ & $0(0)$ \\
Hyperprolactinemia & $\mathrm{I}(0.5)$ & $0(0)$ \\
Blood prolactin increased & $\mathrm{I}(0.5)$ & $0(0)$ \\
Libido decreased & $0(0)$ & $\mathrm{I}(0.2)$ \\
\hline
\end{tabular}

Notes: ${ }^{\mathrm{A}} \mathrm{A}$ subject experiencing more than one adverse event within a system organ class/preferred term is counted once within that system organ class/preferred term for incidence.

size of the study. This multiphase study database provides the longest exposure data currently available with the paliperidone palmitate once-monthly injection in patients early in the course of their illness. Nevertheless, these findings are limited in that this work represents the post hoc analysis of a single study.

Relevant to the tolerability findings, the recently diagnosed and chronically ill subgroups had similar doses, durations of treatment exposure ( $>300$ days in each subgroup), and discontinuation rates. These treatment similarities deserve comment because one might have expected lower doses and/ or shorter exposures to be used in subjects with early illness if they tolerated the drug less well than more chronically ill subjects. ${ }^{5,15,43,56-58}$ However, it is relevant to note that the paliperidone palmitate doses allowed in this study $(39,78,117$, and $156 \mathrm{mg}$ [25, 50, 75, and $100 \mathrm{mg}$ eq]) did not include the highest available $234 \mathrm{mg}$ ( $150 \mathrm{mg}$ eq) dose. Further, initiation doses were lower than the currently recommended initiation dosage (234 mg day 1 and $156 \mathrm{mg}$ day 8 [150 mg eq day 1 and $100 \mathrm{mg}$ eq day 8]). Therefore, while similarities were noted between the two subgroups, the overall rates of adverse events reported during the first month may have been lower than what would have been seen with the currently recommended initiation regimen. Pertinent to this, somewhat higher overall adverse event rates were observed in a recently published post hoc analysis of a double-blind, placebo-controlled trial in recently diagnosed subjects receiving the recommended day 1 and day 8 doses. ${ }^{55}$ During the week following the initial $234 \mathrm{mg}$ (150 mg eq] paliperidone palmitate or placebo injection, $37.6 \%$ (41 of 109) and $29.7 \%$ (11 of 37), respectively, of subjects reported an adverse event. During the month following the day 8 injection of paliperidone palmitate $156 \mathrm{mg}$ (100 mg eq) or placebo, adverse event rates were 41.0\% (16 of 39 ) and $37.8 \%$ (14 of 37), respectively. ${ }^{55}$ During the first week, a broad range of events reported in one or two paliperidone palmitate subjects contributed to the higher rate; the events reported more often by patients on active treatment than by those on placebo were injection site pain, agitation, and headache. In the month following the second injection, anxiety was the most common event, and was reported more often by patients on active treatment than by those on placebo. These events did not emerge as more likely to occur in the recently diagnosed versus more chronic subjects in the present analysis (Figure 2).

Rates of any extrapyramidal symptom-related events, which are of particular concern in patients with early illness,

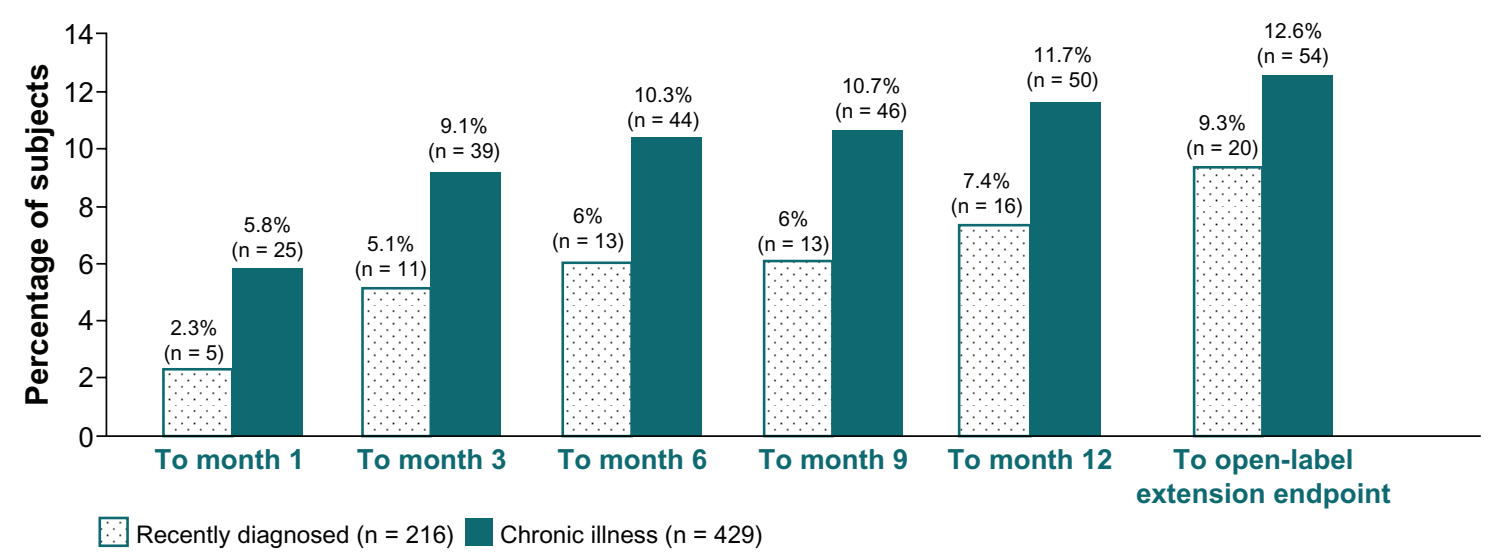

Figure 3 Percentage of Subjects with Any EPS-Related Event* from First Injection to Specified Timepoint, in Recently Diagnosed and Chronic Illness Subjects. Note: *Any EPS-related events include tremor, dystonia, hyperkinesia, parkinsonims, extrapyramidal disorder and dyskinesia, and each of their preferred terms. 
were generally similar or numerically lower in this analysis of recently diagnosed compared with chronically ill subjects. Rates tended to stabilize after month 3 , with incremental increases becoming smaller with continued treatment. Findings related to specific types of extrapyramidal symptoms also require consideration. As reported, there was a somewhat higher rate of nonspecifically coded extrapyramidal symptoms in the recently diagnosed subgroup. In the previously mentioned post hoc analysis of recently diagnosed subjects from a double-blind, placebo-controlled trial, movementrelated event rates were $10.3 \%$ ( 4 of 39 ) with paliperidone palmitate (234 mg day 1 and $156 \mathrm{mg}$ day 8 [150 mg eq day 1 and $100 \mathrm{mg}$ eq day 8 ] and monthly thereafter) and $8.1 \%$ (3 of 37) with placebo over 13 weeks (RR 1.3; 95\% CI $0.30-5.27 ; P>0.05) .{ }^{55}$ Among the specific types of events, the most common in the recently diagnosed population was parkinsonism (7.7\% paliperidone palmitate and $0 \%$ placebo). In the current long-term evaluation, parkinsonism was again the most common movement disorder-related event, with the same rate in recently diagnosed and more chronic subjects $(5.6 \%)$.

Prolactin findings were also anticipated by prior work. ${ }^{55}$ Levels increased in both subgroups and in both sexes, with higher levels in females with early illness compared with those having chronic illness, and a higher percentage of recently diagnosed versus chronically ill subjects reported prolactin-related adverse events $(7.9 \%$ versus $3.5 \%$, respectively).

The limitations to these findings include the fact that the original study was not designed to assess long-term tolerability of the drug in patients with recently diagnosed schizophrenia. The 5-year cut point used to define early illness relied on historical information and patient selfreporting, which may have had variable reliability, and many patients may have been ill for some time prior to receiving a formal diagnosis. Nonetheless, it is generally accepted that the first 5-10 years of illness is a critical period for effective intervention. ${ }^{8-12,24}$ Using this 5-year cut point likely captured a population that was enriched with those at an earlier stage of schizophrenia. Also, although there was no comparison with a placebo group in this analysis, these findings are still relevant to the question at hand regarding the long-term tolerability of paliperidone palmitate in subjects early in the course of their illness compared with those with more chronic illness. An unexpected finding of this safety analysis is the similar or even somewhat lower rate of total adverse events or any extrapyramidal-related events reported by recently diagnosed compared with subjects with chronic illness. This is at variance with other reports in the literature. Also, with few exceptions, baseline phenotypes did not have a significant effect on the results.

In conclusion, these long-term findings complement prior tolerability analyses of the initiation dosing of injectable paliperidone palmitate in subjects with recently diagnosed schizophrenia, ${ }^{55}$ and may help guide clinicians in the management of these patients.

\section{Disclosure}

LA, JKS, D-JF, and CAB are employees of Janssen Scientific Affairs LLC, Titusville, NJ. IT is an employee of Janssen Research and Development LLC, Titusville, NJ. This research was funded by Janssen Scientific Affairs LLC. Writing, editorial, and technical support services were provided by Susan Ruffalo of MedWrite Inc, Newport Coast, CA. Some of these data were presented at the 164th annual meeting of the American Psychiatric Association, held on May 14-18, 2011, Honolulu, HI, and at the 13th International Congress on Schizophrenia Research, April 2-6, 2011, Colorado Springs, CO.

\section{References}

1. Marshall M, Rathbone J. Early intervention for psychosis. Cochrane Database Syst Rev. 2006;4:CD004718.

2. Bartzokis G, Lu PH, Amar CP, et al. Long acting injection versus oral risperidone in first-episode schizophrenia: Differential impact on white matter myelination trajectory. Schizophr Res. 2011; 132:35-41.

3. Kevashan MS, Amirsadri A. Early intervention in schizophrenia: current and future perspectives. Curr Psychiatry Rep. 2007;9: 325-328.

4. Lieberman JA. Is schizophrenia a neurodegenerative disorder? A clinical and neurobiological perspective. Biol Psychiatry. 1999;46:729-739.

5. Lieberman JA, Perkins D, Belger A, et al. The early stages of schizophrenia: speculations on pathogenesis, pathophysiology, and therapeutic approaches. Biol Psychiatry. 2001;50:884-897.

6. Chakos MH, Schobel SA, Gu H, et al. Duration of illness and treatment effects on hippocampal volume in male patients with schizophrenia. $\mathrm{Br}$ J Psychiatry. 2005;186:26-31.

7. Davidson L, McGalshan TH. The varied outcomes of schizophrenia. Can J Psychiatry. 1997;42:34-43.

8. Kelly DL, Conley RR, Carpenter WT. First-episode schizophrenia: a focus on pharmacological treatment and safety considerations. Drugs. 2005;65:1113-1138

9. Harrigan SM, McGorry PD, Krstev H. Does treatment delay in firstepisode psychosis really matter? Psychol Med. 2003;33:97-110.

10. Marshall M, Lewis S, Lockwood A, Drake R, Jones P, Croudace T. Association between duration of untreated psychosis and in cohorts of first-episode outcome patients - a systematic review. Arch Gen Psychiatry. 2005;62:975-983.

11. McGorry PD, Killackey E, Yung AR. Early intervention in psychosis: concepts, evidence and future directions. World Psychiatry. 2008; 7:148-156

12. McGorry PD, Killackey E, Yung AR. Early intervention in psychotic disorders: detection and treatment of the first episode and the critical early stages. Med J Aust. 2007;187(Suppl 7):S8-S10. 
13. Barnes TR, Leeson VC, Mutsatsa SH, Watt HC, Hutton SB, Joyce EM. Duration of untreated psychosis and social function: 1-year follow-up study of first-episode schizophrenia. Br J Psychiatry. 2008;193:203-209.

14. Perkins DO, Gu H, Boteva K, Liberman JA. Relationship between duration of untreated psychosis and outcome in first-episode schizophrenia: a critical review and meta-analysis. Am J Psychiatry. 2005;162:1785-1804.

15. Schooler N, Rabinowitz J, Davidson M, et al. Risperidone and haloperidol in first-episode psychosis: a long-term randomized trial. Am J Psychiatry. 2005;162:947-953.

16. Wyatt RJ. Early intervention with neuroleptics may decrease the longterm morbidity of schizophrenia. Schizophr Res. 1991;5:201-202.

17. Weiden PJ, Schooler NR, Weedon JC, Elmouchtari A, Sunakawa A, Goldfinger SM. A randomized controlled trial of long-acting injectable risperidone vs continuation on oral atypical antipsychotics for first-episode schizophrenia patients: initial adherence outcome. J Clin Psychiatry. 2009;70:1397-1406.

18. Cahn W, van Haren EM, Hulshoff HE, et al. Brain volume changes in the first year of illness and 5-year outcomes of schizophrenia. Br J Psychiatry. 2006;189:381-382.

19. Tiihonen J, Haukka J, Taylor M, Haddad PM, Patel MX, Korhonen P. A nationwide cohort study of oral and depot antipsychotics after first hospitalization for schizophrenia. Am J Psychiatry. 2011;168:603-609.

20. Macfadden W, Bossie CA, Turkoz I, Haskins JT. Risperidone longacting therapy in stable patients with recently diagnosed schizophrenia. Int Clin Psychopharmacol. 2010;25:75-82.

21. Canuso CM, Bossie CA, Amatniek J, Turkoz I, Pandina G, Cornblatt B. Paliperidone extended-release tablets in patients with recently diagnosed schizophrenia. Early Interv Psychiatry. 2010;4:64-78.

22. Allison DB, Casey DE. Antipsychotic-induced weight gain: a review of the literature. J Clin Psychiatry. 2001;62 Suppl 7:22-31.

23. Alvarez-Jimenez M, Gonzalez-Blanch C, Crespo-Facorro B, et al. Antipsychotic-induced weight gain in chronic and first-episode psychotic disorders: a systematic critical reappraisal. CNS Drugs. 2008;22:547-562.

24. Francey SM, Nelson B, Thompson A, Parker AG, Kerr M, MacNeil C. Who needs antipsychotic medication in the earliest stages of psychosis? A reconsideration of benefits, risks, neurology and ethics in the era of early intervention. Schizophr Res. 2010;119:1-10.

25. Llorca PM, Chereau I, Bayle FJ, Lancon C. Tardive dyskinesias and antipsychotics: a review. Eur Psychiatry. 2002;17:129-138.

26. McEvoy JP, Lieberman JA, Perkins DO, et al. Efficacy and tolerability of olanzapine, quetiapine and risperidone in the treatment of early psychosis: a randomized, double-blind 52-week comparison. Am J Psychiatry. 2007;164:1050-1060.

27. Muench J, Carey M. Diabetes mellitus associated with atypical antipsychotic medications: new case report and review of the literature. J Am Board Fam Pract. 2001;14:278-282.

28. Tschoner A, Eng J, Laimer M, et al. Metabolic side effects of antipsychotic medication. Int J Clin Pract. 2007;61:1356-1370.

29. Salimi K, Jarskog LF, Lieberman JA. Antipsychotic drugs for first-episode schizophrenia: a comparative review. CNS Drugs. 2009;23:837-855.

30. Sanger TM, Lieberman JA, Tohen M, Grundy S, Beasley C Jr, Tollefson GD. Olanzapine versus haloperidol treatment in first-episode psychosis. Am J Psychiatry. 1999;156:79-87.

31. Woods SW, Martin A, Spector SG, McGlashan TH. Effects of development on olanzapine-associated adverse events. JAm Acad Child Adolesc Psychiatry. 2002;41:439-446.

32. Wudarsky M, Nicolson R, Hamberger SD, et al. Elevated prolactin in pediatric patients on typical and atypical antipsychotics. JChild Adolesc Psychopharmacol. 1999;9:239-245.

33. Merlo MCG, Hofer H, Gekle W, et al. Risperidone, $2 \mathrm{mg}$ /day vs $4 \mathrm{mg} /$ day, in first-episode, acutely psychotic patients: treatment efficacy and effects on fine motor functioning. J Clin Psychiatry. 2002;63:885-991.
34. Masi G, Cosenza A, Mucci M. Prolactin levels in young children with pervasive developmental disorders during risperidone treatment. $J$ Child Adolesc Psychopharmacol. 2001;11:389-394.

35. Gupta S, Frank B, Madhusodanan S. Risperidone-associated galactorrhea in a male teenager. $J$ Am Acad Child Adolesc Psychiatry. 2001;40:504-505

36. Bobes J, Gilbert J, Ciudad A, et al. Safety and effectiveness of olanzapine versus conventional antipsychotics in the acute treatment of first-episode schizophrenic inpatients. Prog Neuropsychopharmacol Biol Psychiatry. 2003;27:473-481.

37. Kane JM, Garcia-Ribera C. Clinical guideline recommendations for antipsychotic long-acting injections. $B r J$ Psychiatry. 2009;195:63-67.

38. Kozma CM, Slaton T, Dirani R, Gopal S, Fastenau J, Hough D. Changes in schizophrenia-related health-care resource utilization among patients receiving paliperidone palmitate: results of a 52-week clinical trial. Curr Med Res Opin. 2011;27:1603-1611.

39. Schooler NR. Relapse and rehospitalization: comparing oral and depot antipsychotics. J Clin Psychiatry. 2003;64 Suppl 16:14-17.

40. Sheehan J, Fu DJ, Remmerie B, Sliwa JK, Alphs L, Samtani MN. The management of antipsychotic treatment discontinuation and interruptions using model-based simulations. Poster presented at the 51st Annual New Clinical Drug Evaluation Unit New Research Approaches for Mental Health Interventions Meeting, June 13-16, 2011, Boca Raton, FL.

41. Zhu B, Ascher-Svanum H, Shi LB, et al. Time to discontinuation of depot and oral first-generation antipsychotics in the usual care of schizophrenia. Psychiatr Serv. 2008;59:315-317.

42. Parellada E, Andrezina R, Milanova V, et al. Patients in the early phases of schizophrenia and schizoaffective disorders effectively treated with risperidone long-acting injectable. J Psychopharmacol. 2005;19:5-14

43. Emsley R, Medori R, Koen L, Oosthuizen PP, Niehaus D, Rabinowitz J. Long-acting injectable risperidone in the treatment of subjects with recent-onset psychosis: a preliminary study. J Clin Psychopharmacol. 2008;28:210-213

44. Napryeyenko O, Burba B, Martinez G, et al. Risperidone longacting injectable in recent-onset schizophrenia examined with clinician and patient self-report measures. J Clin Psychopharmacol. 2010;30:200-202.

45. Dubois V, Megens J, Mertens C, et al. Long-acting risperidone in early-episode schizophrenia. Acta Psychiatric Belg. 2011;111:9-21.

46. Kim B, Lee SH, Choi TK, et al. Effectiveness of risperidone long-acting injection in first-episode schizophrenia: in naturalistic setting. Prog Neuropsychopharmacol Biol Psychiatry. 2008;32:1231-1235.

47. Invega ${ }^{\circledR}$ Sustenna ${ }^{\circledast}$ (paliperidone palmitate, full prescribing information). Titusville, NJ: Janssen Pharmaceuticals Inc; Sep 2011.

48. Gopal S, Hough DW, Xu H, Lull JM, Gassmann-Mayer C, Remmerie BM. Efficacy and safety of paliperidone palmitate in adult patients with acutely symptomatic schizophrenia: a randomized double-blind, placebo-controlled, dose-response study. Int Clin Psychopharmacol. 2010;25:247-256.

49. Hough D, Lindenmayer JP, Gopal S, et al. Safety and tolerability of deltoid and gluteal injections of paliperidone palmitate in schizophrenia. Prog Neuropsychopharmacol Biol Psychiatry. 2009;33: 1022-1031.

50. Nasrallah H, Gopal S, Gassmann-Mayer C, et al. A controlled, evidencebased trial of paliperidone palmitate, a long-acting injectable antipsychotic, in schizophrenia. Neuropsychopharmacol. 2010;35:2072-2082.

51. Pandina G, Lindenmayer JP, Lull J, et al. A randomized, placebocontrolled study to assess the efficacy and safety of three doses of paliperidone palmitate in adults with acutely exacerbated schizophrenia. J Clin Psychopharmacol. 2010;30:235-244.

52. Hough D, Gopal S, Vijapurkar U, Lim P, Morozova M, Eerdekens M. Paliperidone palmitate maintenance treatment in delaying the time-to-relapse in patients with schizophrenia: a randomized, doubleblind, placebo-controlled study. Schizophr Res. 2010;116:107-117. 
53. Coppola D, Liu Y, Gopal S, et al. Long-term safety, tolerability and pharmacokinetics of the highest available dose of paliperidone palmitate: a one-year open-label study in patients with schizophrenia. Poster presented at the American Society of Clinical Pharmacology and Therapeutics annual meeting, March 17-21, 2010, Atlanta, GA.

54. Gopal S, Vijapurkar U, Lim P, Morozova M, Eerdekens M, Hough D. A 52-week open-label study of the safety and tolerability of paliperidone palmitate in patients with schizophrenia. JPsychopharmacol. 2011;25:685-697.

55. Bossie CA, Fu DJ, Sliwa JK, Ma YW, Alphs L. Tolerability of initiation doses of once-monthly paliperidone palmitate in subjects with recently diagnosed schizophrenia in an acute treatment trial. Ther Adv Psychopharmacol. 2011;1:111-124.
56. Lasser RA, Bossie CA, Zhu Y, Locklear JC, Kane JM. Long-acting risperidone in young adults with early schizophrenia or schizoaffective illness. Ann Clin Psychiatry. 2007;19:65-71.

57. International Early Psychosis Association Writing Group. International clinical practice guidelines for early psychosis. Br J Psychiatry. 2005;187 Suppl 48:S120-S124.

58. Weiden PJ, Buckley PF, Grody M. Understanding and treating "firstepisode" schizophrenia. Psychiatr Clin North Am. 2007;30:481-510.

Neuropsychiatric Disease and Treatment

\section{Publish your work in this journal}

Neuropsychiatric Disease and Treatment is an international, peerreviewed journal of clinical therapeutics and pharmacology focusing on concise rapid reporting of clinical or pre-clinical studies on a range of neuropsychiatric and neurological disorders. This journal is indexed on PubMed Central, the 'PsycINFO' database and CAS.
The manuscript management system is completely online and includes a very quick and fair peer-review system, which is all easy to use. Visit http://www.dovepress.com/testimonials.php to read real quotes from published authors.

Submit your manuscript here: http://www.dovepress.com/neuropsychiatric-disease-and-treatment-journal 